\title{
JUSTIÇA TRANSICIONAL NO CHILE PÓS-DITADURA MILITAR: A QUES- TÃO DA IMPUNIDADE NA LITERATURA DE ROBERTO BOLAÑO
}

\author{
Marcela Vieira Martins (História- UEL) \\ Prof. Dr. André Lopes Ferreira (Orientador) \\ marcelablackbird@yahoo.com.br
}

\section{RESUMO}

O intuito do presente trabalho é realizar uma investigação histórica sobre o tema da impunidade no Chile pós- ditadura militar. A sociedade chilena, além do desafio de realizar a transição para a democracia, teve que lidar com a questão da violação dos direitos humanos durante os mais de vinte anos de ditadura.

O Chile enfrentou um longo e violento regime de exceção de 1973 até 1990, com o número de torturados e assassinados chegando aos milhares. A quantidade de exilados também foi altíssima chegando a 20.000 até 1983. Roberto Bolaño Ávalos foi um desses exilados. $\mathrm{O}$ escritor chileno foi preso logo após o golpe militar e decidiu se exilar na Espanha, país no qual trabalhou em pequenos empregos e desenvolveu atividade como poeta e escritor de romances, ressaltando que só teve reconhecimento pelo seu trabalho na literatura no fim de sua vida.

Nesse estudo partimos da hipótese de que dois livros escritor por Roberto Bolaño, La literatura nazi em América e Estrella distante, ambos de 1996, podem ser objetos de estudo para analisar a transição chilena à democracia e as questões que permearam essa transição, como o direito à justiça e à verdade, a memória pessoal e coletiva e, especialmente, a impunidade.

Palavras- chave: justiça transicional, impunidade, literatura.

Com o encerramento da ditadura pinochetista em 1990, a sociedade e as forças políticas chilenas viram-se diante do desafio de consolidar a recém-conquistada democracia e, ao mesmo tempo, lidar com a questão da violação de direitos humanos por agentes do Estado durante o longo governo (1973- 1990) do General Augusto Pinochet. Mesmo com a saída da junta militar do governo do Chile não foi tão simples e rápido levar á justiça esses militares criminosos, especialmente porque antes de sair do governo os mesmos deixaram vários entraves que os deixavam inalcançáveis para qualquer tipo de justiça. Manuel Antonio Garreton elucida melhor o que aconteceu após a derrota de Pinochet em um plebiscito de 1988, onde foi decidido que ele não estaria mais no poder

[...] a derrota política sofrida por Augusto Pinochet e pelo regime militar no plebiscito de 5 de outubro teve um duplo significado. Por um lado, pôs fim à pretensão de projetar a ditadura através de um regime autoritário como o previsto pela Constituição de 80 e o projeto de $\mathrm{Au}-$ gusto Pinochet de manter-se no poder para assegurar essa passagem da ditadura militar para o regime autoritário. Por outro lado, desencadeou um processo de transição para a democracia, que se desenvolve dentro de prazos e através de mecanismos estabelecidos pelo regime mas 


\section{SEMINÁRIO DE PESQUISA EM CIÊNCIAS HUMANAS - SEPECH \\ Humanidades, Estado e desafios didático-científicos \\ Londrina, 27 a 29 de julho de 2016}

modificados em parte pela oposição, e por ela alterados substancialmente em seu significado [...] (GARRETON, 1992)

Assim, o início do processo de transição no Chile se deu em termos de uma transição consensual com a ajuda das Forças Armadas e garantias da mesma para que a transição fosse bem sucedida. Garreton ainda lembra que a transição chilena não poderia ser considerada completamente terminada assim que se instaura o novo governo democrático, ela será um longo processo que herdou vários vícios e enclaves autoritários do antigo regime militar, como a já citada lei de anistia de 1978.

Juntamente com a transição para a democracia começa a se pensar em algum modo de se fazer justiça às vitimas da ditadura e meios possíveis de condenar aqueles que cometeram crimes contra os direitos humanos. Para isso emerge o conceito de justiça transicional, utilizado principalmente nos países da América Latina que passaram por um longo período de governos repressivos e autoritários, marcados pela violência e abuso contra seus cidadãos e violações massivas dos direitos humanos. Paul van Zyl define justiça transicional como uma maneira de se construir uma paz democrática após um longo período de violência sistemática, que tem como objetivos processar aqueles que cometeram crimes de lesa humanidade, revelar a verdade sobre esses crimes, fornecer meios de reparação às vítimas, reformas as instituições criminosas e promover a reconciliação (VAN ZYL, 2011, p. 47). Esforços por parte da sociedade civil e medidas por parte do governo são tomados para que o momento que a sociedade vivenciava antes da redemocratização, como conflitos e violações dos direitos humanos não volte a acontecer. Assim, a justiça transicional pretende olhar para o passado, encarar seu teor violento e pensar o que acontecia em tal momento, mas ao mesmo tempo projeta para o futuro uma sociedade melhor, na qual a cidadania como um todo reconheça que erros foram cometidos e que trabalhem em conjunto para que isso não se repita.

Com a vitória de Patricio Aylwin, candidato à presidência pela Concertación de Partidos por Ia Democracia na primeira eleição democrática chilena desde 1970, foi criada em 1990 uma comissão da verdade, chamada de Comissão Nacional de Verdade e Reconciliação ou Comissão Rettig para investigar os crimes de desaparecimento e morte que ocorreram durante a ditadura. Burt esclarece como funcionou a comissão da verdade afirmando que

[...] temendo uma reação militar, o governo de Aylwin não contestou a lei de anistia de 1978, decretado sob o governo de Pinochet para impedir punição pelos piores crimes da ditadura. A Comissão Rettig, como é conhecida, investigou execuções extrajudiciais, desaparecimentos e casos de tortura que levaram à morte (mas não tortura por si só). Produziu um relatório documentando a morte e o desaparecimento de cerca de 3.000 cidadãos chilenos e recomendou a implementação de reparações monetárias e simbólicas para os sobreviventes da ditadura. A impunidade, entretanto, permaneceu intacta. Embora houvesse julgamentos investigando casos de desaparecimentos forçados e assassinato, a lei de anistia era rotineiramente aplicada, protegendo os criminosos da punição efetiva [...] (BURT, 2011, p.318)

A lei de Anistia de 1978 foi um dos maiores entraves no tocante à punição dos crimes ocorridos durante a ditadura, já que tolhia a capacidade do Poder Judiciário de 


\title{
XI SEMINÁRIO DE PESQUISA EM CIÊNCIAS HUMANAS - SEPECH \\ Humanidades, Estado e desafios didático-científicos \\ Londrina, 27 a 29 de julho de 2016
}

levar a cabo os julgamentos daqueles que cometeram crimes de lesa humanidade. Assim, Aylwin resolveu optar por medidas de caráter simbólico que visavam reforçar o papel da memória coletiva e para que atitudes repressivas não ocorressem novamente (DAUER, 2015).

José Zalaquett, membro da Comissão Rettig, em entrevista a Naomi Roth- Arriaza, afirma que apesar da justiça penal ser um clamor popular, às vezes ela pode ser inviável em uma sociedade que acaba de sair de um período de repressão, para ele

\begin{abstract}
Quando alguém pensa em como enfrentar as violações de direitos humanos como parte do processo de construção ou reconstrução moral, o primeiro modelo que vem à mente, naturalmente, é o da justiça penal. Afinal, trata-se de crimes atrozes e, em sua maioria, massivos. Porém, este modelo está desenhado para fazer cumprir uma ordem justa que já existe, e não, necessariamente, para reconstruir uma depois de um período de destruição, [...] o julgamento das violações de direitos humanos é um dos principais elementos a ser considerado no desenho de políticas durante um período de transição [...] (ARRIAZA, 2011, p.173-174)
\end{abstract}

Zalaquett defende a ideia de que para alcançar a reconstrução de uma ordem justa é preciso adotar medidas especificas para cada tipo de situação. Assim para o caso do Chile foi analisado até que ponto seria viável usar medidas de punição assim como a reconciliação, levando à conclusão que revelando a verdade sobre crimes do passado eventualmente levaria a punição de culpados e se isso não fosse possível, pelo menos levaria a uma reconciliação entre vitimas e algozes.

Verdade é que a Comissão Rettig apesar de importante no que tange às questões da memória e verdade durante a transição, só pôde ir até certo ponto. Jo- Marie Burt sobre tal aponta que

[...] o pragmatismo era regra geral em tais democracias em transição, como indica a frase bem conhecida do comissionado, membro da comissão da verdade chilena, José Zalaquett, cuja famosa formulação pedindo aos governantes políticos que buscassem justiça "dentro do possível" alimentou uma construção binária que afirmou que a verdade era uma alternativa aceitável à justiça [...] (BURT, 2011, p.309).

O propósito da punição em sociedades que estão saindo da ditadura e lutando para estabelecer a democracia, não é somente restaurar o Estado de Direto ou porque ele protege o sujeito de outros poderes da sociedade. Por respeito às normas que pró́bem atos como tortura, assassinatos patrocinados pelo Estado, desaparecimentos e outras violações dos direitos humanos, esses atos devem ser punidos. A punição desses diz nas entrelinhas que essa sociedade não mais irá tolerar essas violações, que não haverá réus privilegiados e que a situação das vitimas não será esquecida (MÉNDEZ, 2011, p. 219).

As investigações penais no Chile só avançaram a partir de agosto de 1999, quando se estabelece uma mesa de diálogo entre vários setores da sociedade chilena, incluindo militares, com o objetivo de encontrar as vítimas do regime militar ou pelo menos saber qual foi seu destino. É válido lembrar que a mesa de diálogo ocorreu concomitantemente à prisão de Augusto Pinochet em Londres, o que gerou um complexo 


\section{SEMINÁRIO DE PESQUISA EM CIÊNCIAS HUMANAS - SEPECH \\ Humanidades, Estado e desafios didático-científicos \\ Londrina, 27 a 29 de julho de 2016}

debate sobre o tratamento dado aos casos das vítimas da ditadura e sobre a possibilidade da penalização desses crimes.

O resultado da mesa de diálogos veio à tona em janeiro de 2001. Os militares apresentaram qual foi o destino de 200 vítimas, sendo 180 identificadas. O então presidente Ricardo Lagos entregou essas informações a Suprema Corte e solicitou um reforço às instancias judiciais para atender a demanda dessas vítimas e seus familiares. Com essas designações feitas por Lagos as investigações conseguiram avançar muito e melhorar qualitativamente, reabrindo-se processos, ampliando-se estas nomeações e, no ano de 2005, reorganizando este trabalho e facultando às Cortes de Apelação das regiões para designar ministros investigadores.

Já em 2011 a Suprema Corte abriu investigação penal de 700 casos que até então não tinham tido nenhuma investigação penal, inclusive uma investigação para estabelecer a causa da morte do ex-presidente Salvador Allende. De fato os tribunais de justiça estavam dispostos a investigar e estabelecer sanções penais aos responsáveis, porém, a Suprema Corte agiu de maneira errática na hora de aplicá- lás (PEREIRA, 2011, p.299).

Cabe ainda ressaltar que mesmo diante de tantas conquistas a justiça transicional no Chile falhou em um dos seus aspectos mais importantes, a remoção dos violadores de direitos humanos dos cargos políticos. Pinochet ocupou até 2002 o cargo de senador vitalício (criado por ele mesmo), quando renunciou por causa de problemas de saúde e as constantes denúncias de violação dos direitos humanos. Paul Van Zyl afirma que

[...] a presença em altos cargos governamentais de pessoas direta ou indiretamente responsáveis das violações generalizadas ou sistemáticas de direitos humanos constitui um fator de predição a respeito do ressurgimento ou a continuação do conflito. Ao contrário, a remoção das mencionadas pessoas de seus cargos pode ser de aporte vital para a construção da paz pós- conflito [...]. (VAN ZYL, 2011, p.57-58)

Outro exemplo é o de Cristián Labbé que foi prefeito da comuna de Providencia por dezesseis anos, de 1996 até 2012. Labbé foi um conhecido agente do DINA, ministro secretário do regime militar entre 1989 e 1990 e nunca foi condenado por nenhum crime. Enquanto Pinochet esteve preso em Londres, Labbé viajou para a Inglaterra 14 vezes para visitá-lo, e enquanto prefeito quis homenagear outro conhecido agente do DINA, Miguel Krassnoff, vulgo "caballo loco", que sozinho tem mais de 20 condenações e atualmente cumpre uma pena de 120 anos em Punta Peuco.

Outro aspecto da justiça de transição diz respeito à condenação dos violadores de direitos humanos em escala vertical, de forma que os maiores responsáveis por essas violações são julgados primeiro, isto é, sendo feitas as acusações de cima para baixo. Augusto Pinochet não respondeu em vida por nenhum de seus crimes, não ficou nenhum dia em um presídio. Após dois anos de cárcere privado em Londres ${ }^{1}$, em março de 2000 foi extraditado para o Chile por pressão da direita e dos militares. A mesma justiça que durante anos se calou ante os pedidos de investigação de vítimas da ditadura e de seus familiares fez vista grossa às mais de 300 queixas contra Pinochet, que morreu em 2006 em sua residência de luxo em um bairro nobre de Santiago.

\footnotetext{
${ }^{1}$ Pinochet foi preso em 1998 em Londres por causa do principio da extraterritorialidade da lei penal em matéria de delitos de lesa-humanidade.
} 


\section{SEMINÁRIO DE PESQUISA EM CIÊNCIAS HUMANAS - SEPECH \\ Humanidades, Estado e desafios didático-científicos \\ Londrina, 27 a 29 de julho de 2016}

Há de se questionar também a prisão do "braço direito" de Pinochet entre 1973 e 1978, Manuel Contreras. Contreras, que foi chefe do DINA e liderou por ordem de Pinochet caçadas internacionais a opositores do regime militar, foi o principal articulador do atentado que matou o diplomata chileno Orlando Letelier e sua assistente em 1976 em Washington. A condenação de Contreras em 1993 só foi levada adiante por causa da pressão dos Estados Unidos.

A prisão Punta Peuco também é alvo de fortes críticas por parte da esquerda chilena. A Penal Punta Peuco foi criada em 1995 durante o governo de Eduardo Frei RuizTagle e é um centro de detenção feito especialmente para militares e agentes do Estado envolvidos na violação de direitos humanos durante a ditadura; note-se que é administrada também por militares. Em 2012 veio à tona um informe sobre as condições em que viviam os presos em Punta Peuco, o qual constatou que os mesmos desfrutavam de vários privilégios como piscina, acesso a internet, telefone e celas individuais.

O Informe Rettig também é duramente criticado já que se centrou na reparação, mas não da justiça. A doutrina implícita na frase "justiça na medida do possível", que Aylwin e Zalaquett acreditavam, servia para manter o sistema econômico estabelecido na ditadura, suas leis de trabalho, política de privatização da saúde e da educação, e para não perturbar a fragilidade política na qual o Chile se encontrava após sair da ditadura.

Desde 2014 a então presidente do Chile, Michelle Bachelet pretende derrubar a lei de Anistia. Em um pronunciamento em 11 de setembro de 2014 ao lembrar o 41 ${ }^{\circ}$ aniversário do golpe de 1973, Bachelet disse que "muchos han muerto a la espera de la justicia, muchos han muerto guardando silencio. Basta ya de esperas dolorosas y de silencios injustificados. [...] es el momento de hermanarnos en la verdad.". A fala de Bachelett é importante, pois de maneira simbólica oferece conforto aos que sobreviveram a ditadura pinochetista ao saber que criminosos do período da ditadura não tem uma lei especial que os protejam do alcance da justiça. Apesar de esse pronunciamento ter causado um efeito positivo, até a data de fechamento desse artigo a Lei da anistia continua sendo debatida no congresso chileno.

O Chile percorreu um longo caminho feito de negociações e concessões até chegar nesse ponto onde se pode debater a validade da anistia de 78. Por mais que pareça que o país tenha avançado muito no que diz respeito à punição por crimes ocorridos na ditadura, principalmente em comparação aos outros países do cone sul, somente poucos foram realmente condenados no judiciário por seus crimes. Segundo o relatório de 2014 do Programa de Derechos Humanos o número de causas que permaneciam abertas em todo o Chile por crimes de lesa humanidade ocorridos durante a ditadura era de 1.045, sendo de 1.073 de ex-agentes processados, acusados e condenados; destes, 281 têm uma sentença definitiva, mas somente 75 cumprem pena de prisão efetiva.

O principal objetivo deste trabalho é analisar como as questões discutidas acima sobre a justiça transicional e impunidade no Chile pós- ditadura militar refletiram sobre duas obras de 1996 do escritor Roberto Bolaño, La literatura nazi en América e Estrella distante. Bolaño utiliza a literatura como um espaço de reflexão, crítica e denúncia justamente em um período pródigo em debates sobre as violações de direitos humanos durante a ditadura militar, assim me parece que os livros de Bolaño são testemunhas de seu tempo. Mesmo que sendo obras de ficção para sua criação o escritor mescla fatos a partir do mundo real e de sua memória pessoal, especialmente evidente no caso de Bolaño, que foi preso durante os primeiros meses do golpe e após ser solto se exilou na Espanha onde viveu até sua morte em 2003. 


\section{SEMINÁRIO DE PESQUISA EM CIÊNCIAS HUMANAS - SEPECH \\ Humanidades, Estado e desafios didático-científicos \\ Londrina, 27 a 29 de julho de 2016}

Bolaño utiliza um recurso muito caro aos escritores latino-americanos que é a ficcionalização da história em uma tentativa de dar voz àqueles marginalizados e oprimidos pela sociedade por meio de uma narrativa ficcional. Assim a literatura de Roberto Bolaño não será entendida somente como obras de caráter ficcional, mas que de alguma maneira apresenta as demandas da sociedade chilena nos anos 90 pela justiça e memória as vítimas do regime militar.

\section{REFERÊNCIAS}

ARRIAZA, Naomi Roth. A necessidade de reconstrução moral frente às violações de direitos humanos cometidas no passado: uma entrevista com José Zalaquett. In: REÁTEGUI, F. (Org). Justiça de transição: manual para a América Latina. Brasília: Ministério da justiça, 2011. p. 171-189.

BURT, Jo Marie. Desafiando a impunidade nas cortes domésticas: processos pelas violações de direitos humanos na América Latina. In: REÁTEGUI, F. (Org). Justiça de transição: manual para a América Latina. Brasília: Ministério da justiça, 2011. p. 307- 335 .

DAUER, Gabriel Roberto. Marcas da memória: justiça de transição no Brasil e Chile. Disponível em: https://www.ufrgs.br/sicp/wp-content/uploads/2015/09/4.-DAUERGabriel-Roberto-Marcas-da-Mem\%C3\%B3ria-justi\%C3\%A7a-detransi\%C3\%A7\%C3\%A3o-no-Brasil-e-no-Chile.pdf. Acesso em: 19 out. 2015.

GARRETÓN, Manuel Antonio M. A redemocratização no Chile: transição, inauguração, evolução. Disponível em: http://www.scielo.br/scielo.php?s01026445199200030000\&script=sci_arttext. Acesso em: 14 set. 2015.

MARENGO, G. Chile: La ley de amnistía mantiene vivo el legado de Pinochet. Disponível em:http://internacional.elpais.com/internacional/2015/09/11/actualid ad/1441979718_729729.html. Acesso em: 09 maio 2016.

MÉNDEZ, Juan E. Responsabilização por abusos do passado. In: REÁTEGUI, F. (Org). Justiça de transição: manual para a América Latina. Brasília: Ministério da justiça, 2011. p. 193-225.

PEREIRA, Pamela. Os caminhos da judicialização: uma observação do caso chileno. In: REÁTEGUI, F. (Org). Justiça de transição: manual para a América Latina. Brasília: Ministério da justiça, 2011. p. 291- 305.

VAN ZYL, Paul. Promovendo a justiça transicional em sociedades pós- conflito. In: REÁTEGUI, F. (Org). Justiça de transição: manual para a América Latina. Brasília: Ministério da justiça, 2011.p. 47- 71. 